Article

\title{
Preliminary Study on the Use of Biodiesel Obtained from Waste Vegetable Oils for Blending with Hydrotreated Kerosene Fossil Fuel Using Calcium Oxide (CaO) from Natural Waste Materials as Heterogeneous Catalyst
}

\author{
S. Ozkan ${ }^{1}$, J. F. Puna ${ }^{2,3}$ () J. F. Gomes ${ }^{2,3, *}$, T. Cabrita ${ }^{2}$, J. V. Palmeira ${ }^{2,3}$ and M. T. Santos ${ }^{2}$ \\ 1 Kocaeli Üniversitesi Umuttepe Yerleşkesi, 41380 Kocaeli, Turkey; silaozkann@gmail.com \\ 2 Área Departamental de Engenharia Química, Instituto Superior de Engenharia de Lisboa, \\ Instituto Politécnico de Lisboa, R. Conselheiro Emídio Navarro 1, 1959-007 Lisboa, Portugal; \\ jpuna@deq.isel.ipl.pt (J.F.P.); tcabrita@deq.isel.ipl.pt (T.C.); vpalmeira@deq.isel.ipl.pt (J.V.P.); \\ tsantos@deq.isel.ipl.pt (M.T.S.) \\ 3 CERENA-Centro de Recursos Naturais e Ambiente, Instituto Superior Técnico, Universidade de Lisboa, \\ Av. Rovisco Pais 1, 1049-001 Lisboa, Portugal \\ * Correspondence: jgomes@deq.isel.ipl; Tel.: +351-96-390-2456
}

Received: 23 September 2019; Accepted: 7 November 2019; Published: 12 November 2019

\begin{abstract}
In this experimental work, calcium from natural seafood wastes was used as a heterogeneous catalyst separately or in a blend of "shell mix" for producing biodiesel. Several chemical reaction runs were conducted at varied reaction times ranging from $30 \mathrm{~min}$ to $8 \mathrm{~h}$, at $60^{\circ} \mathrm{C}$, with a mass content of $5 \%\left(\mathrm{~W}_{\text {cat. }} / \mathrm{W}_{\text {oil }}\right)$ and a methanol/oil molar ratio of 12 . After the purification process, the biodiesel with fatty acid methyl ester (FAME) weight content measured was higher than $99 \%$, which indicated that it was a pure biodiesel. This work also showed that the inorganic solid waste shell mixture used as the heterogeneous catalyst can be reused three times and the reused mixture still resulted in a FAME content higher than $99 \%$. After 40 different transesterification reactions were performed using liquid (waste cooking oils) and solid (calcium seafood shells) wastes for producing biodiesel, under the specific conditions stated above, we found a successful, innovative, and promising way to produce biodiesel. In addition, blends prepared with jet fuel A1 and biodiesel were recorded with no invalid results after certain tests, at $25^{\circ} \mathrm{C}$. In this case, except for the $10 \%$ blend, the added biodiesel had no significant effect on the viscosity (fluidity) of the biojet fuel.
\end{abstract}

Keywords: biodiesel; seafood inorganic wastes; calcium oxide; transesterification; hydrotreated kerosene; heterogeneous catalysis

\section{Introduction}

Aviation fuel, a petroleum-based fuel used to power aircraft, has strict quality requirements in air transport [1]. Jet fuel is an aviation fuel designed specifically to power gas-turbine engines. According to a report from the U.S. Energy Information Administration in 2013, "4 gallons out of every 42-gallon barrel of crude oil are used to produce jet fuel". The worldwide aviation industry consumes approximately 1.5-1.7 billion barrels of conventional jet fuel (JET-A1) per year. Several homegrown and renewable feedstock-based fuel systems are critical in the strategy to achieve energy security and improve environmental sustainability. In 2010, the U.S. Department of Agriculture (USDA) and the Navy inaugurated a joint venture called "Farm-to-Fleet" to develop domestic, competitively priced, diesel and jet fuel replacements (USDA News Release 2013). The Farm-to-Fleet program announced 
in 2013 that it incorporates the acquisition of biofuel blends into regular domestic exactions for jet engine and marine diesel fuels (USDA News Release 2013). The Navy will seek to purchase JP-5 and F-76 advanced drop-in biofuels blended with $10-50 \%$ conventional fuels. There are many processual technologies to convert biomass-based materials into jet fuel [2]. Some are available on a commercial or pre-commercial scale, while others are still under research and development [3]. Global airline operations consumed approximately 1.5 billion barrels of Jet A- 1 fuel producing 705 million metric tons (Mt) of $\mathrm{CO}_{2}$ in 2013, producing just under $2 \%$ of the total of $\mathrm{CO}_{2}$ emissions [4]. Until 2050, worldwide aviation is expecting to grow by up to $5 \%$ annually, with the following target: 12 million tons per year. CO emissions from aviation in 2012 in Europe represented 12.9\% of total transport emissions. Final energy consumption in aviation in 2012 was 49.1 million tons equivalent (Mtoe) or $14 \%$ of transport energy usage. Adding biofuel to hydrotreated kerosene fossil fuel lowers the $\mathrm{CO} / \mathrm{CO}_{2}$ (carbon monoxide/dioxide) and NOx (nitric oxide) Green House Gas (GHG) emissions [5]. The difference between pure biofuel (B100) and fuel oil performance was $40 \%$ less for $\mathrm{CO}$ and $50 \%$ less for $\mathrm{CO}_{2}$ GHG emissions. For all fuels, NOx concentration increased a little $(<5 \%)$ and $\mathrm{CO} / \mathrm{CO}_{2}$ concentration decreased significantly. In general, previous studies suggest that, the addition of biofuel to fossil fuel reduced the static thrust and increased the fuel consumption by as much as $8 \%$ and $4 \%$, respectively, due to the lower heat content of biofuel [6]. The presence of oxygen in biofuel molecules was expected to result in a cleaner combustion, and therefore increase the thermal efficiency, and a little increase in NOx emissions. As biodiesel is a renewable fuel, it has many advantages when compared to fossil fuels [7]. First of all, it is non-toxic, biodegradable, and does not ignite easily due to its high flash point, making it more advantageous than most fossil fuels. It is easy to transport and store it. In addition, some other advantageous reasons can be pointed out, such as, the fact that, it does not contain sulfur, it does not increase $\mathrm{CO}_{2}$ emissions, and is produced from a renewable energy source, like the lipid biomass which can be found in oleaginous plants (rapeseed, palm, soya, sunflower, and jatropha), thus minimizing the GHG emissions [8,9]. Due to the utilization of calcium seafood wastes and vegetable oils as heterogeneous catalysts and raw materials, respectively, in biodiesel production, it promotes, twice, the sustainability of this process. Other advantages are related to the fact that biodiesel is suitable for use in diesel motor vehicles at a blend ratio less than $30 \%$, does not require any modifications, and does not adversely affect the engine performance $[10,11]$. On the other hand, CO emissions are reduced by $50 \%$ and particulate matter by $30 \%$. Sulfates, which cause acid rain, are eliminated. Aldehyde compounds are reduced by $30 \%$ and hydrocarbon emissions by $95 \%$, when compared with the conventional diesel. In 2018, biodiesel represented $58 \%$ of the global biofuel production around the world, while bioethanol represented $39 \%$ of that production and the remaining $3 \%$ corresponded to biomethanol, biomethane, and other biofuels [12]. Figure 1 [12] shows the evolution of biodiesel and bioethanol global productions over the last 10 years. There are different methods used for biodiesel production, such as pyrolysis, dilution, transesterification, supercritical method, microwave-assisted transesterification, and ultrasound-assisted transesterification [13]. To date, different solid alkali catalysts have been developed for the production of biodiesel [14], such as zeolite, alkaline earth metal oxide [15], and hydrotalcites [16]. Alkali earth metal oxides, especially calcium oxide (CaO), are highly prominent due to their high basic strength and low solubility in methanol $[17,18]$. Natural Ca-rich minerals can also be used as precursors for CaO catalysts [14,19], but these materials can also be produced from seafood inorganic wastes $[20,21]$, such as white seashells, "navalha" shells, waste obtuse horn shells [22], combusted oyster shells [23], mud crab (Scylla serrata) shells [24], Ca industrial wastes [25], mollusk shells, shrimp shells, and eggshells [26,27]. Basically, the activation processes of these materials only need a simple calcination process, up to $850^{\circ} \mathrm{C}$, to convert calcium carbonate into calcium oxide, the active species for these catalysts. In another study [11], it was observed how steam and carbon dioxide reacted with these materials, thus affecting the catalytic performance and behavior of active $\mathrm{CaO}$. The study showed that $\mathrm{CaO}$ was rapidly hydrated and carbonated in air, and no $\mathrm{CaO}$ peak was observed after exposure to air for more than 20 days. $\mathrm{CaO}$, which also shows a tendency to easily deactivate with these poisons $\left(\mathrm{CO}_{2}\right.$ and $\left.\mathrm{H}_{2} \mathrm{O}\right)$, can recover its catalytic activity if recalcination is 
applied. Also, several studies have been conducted to investigate the use of other natural materials as catalysts, such as snail shell [28,29] and rice husks [30], while a wide range of bio-based materials have also been reviewed recently [31]. Finally, regarding the utilization of liquid wastes to produce biodiesel, particularly waste cooking oils (WCO), by using calcium seafood wastes or the typical calcium oxide as heterogeneous catalysts, several works highlighted that higher FAME yields $(>99 \%)$ are achievable with these wastes. These are very promising results for biodiesel production with high quality standards [32-36], which can improve the importance of recycling wastes, thereby decreasing the raw material costs.

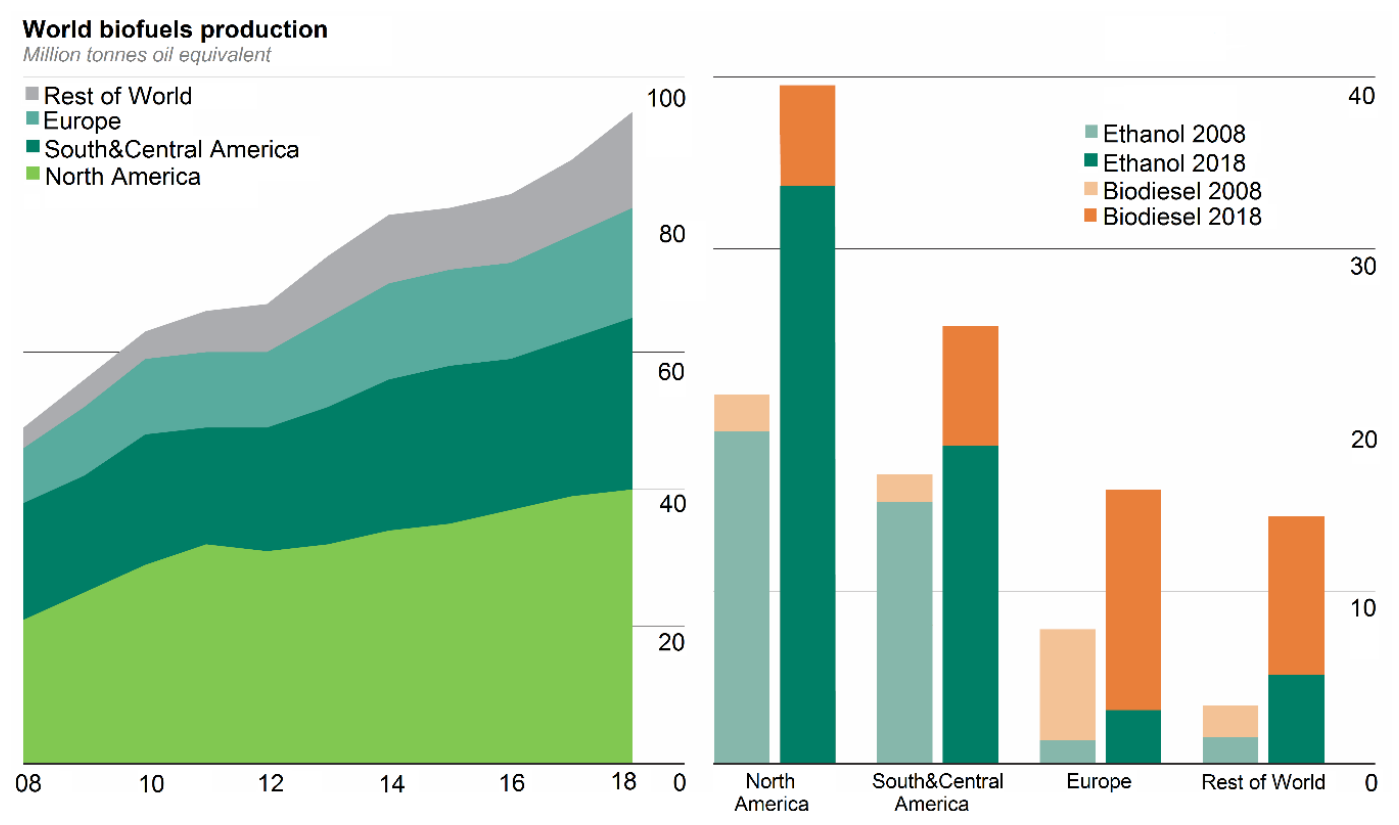

Figure 1. Global production of biodiesel and bioethanol in 2008 and 2018 [12].

\section{Materials and Methods}

\subsection{Chemicals}

The chemicals used in these experiments were phosphoric acid $85 \%(w / w)$ and potassium hydroxide $85 \%(w / w)$ from PANREAC (Barcelona, Spain); sodium hydroxide pellets from LABCHEM (Zelienople, PA, USA); citric acid; hydrated solid, pure acetone as solvent from Jose Manuel Gomes Dos Santos, Lda. (Odivelas, Portugal); ethanol $>99.5 \%(w / w)$ and nitric acid $65 \%(w / w)$ from MERCK (Darmstad, Germany); methanol $>99.5 \%(w / w)$ from CARLO ERBA (Le Vaudreuil, France); and hydrotreated kerosene (JET-A1) fuel manufactured and provided by a Portuguese refining crude oil company.

\subsection{Equipment Used}

Several equipment were used to achieve the various objectives of this research work as follows: Two heating baths, a LAUDA Ecoline 019 water bath with the LAUDA E100 heating system from LAUDA-Brinkmann LP (Delran, NJ, USA) and a water thermostatic bath with cooler, model F32, from JULABO Labortechnik (Seebach, Germany) as well as two mechanical stirrers from the LBX OS20 series (Labbox Labware, Barcelona, Spain) to perform the transesterification reactions; a vacuum pump from Comecta Ivymen (Comecta, Barcelona, Spain) to perform the vacuum filtration step in order to collect the catalyst samples after the transesterification process; an analytical balance, KERN EMB-V (KERN \& SOHN GmbH, Balingen, Germany), to weigh the mass catalyst and prepare the solutions; an oven from ERT, Lda. (Setúbal, Portugal) to dry the catalyst samples; a furnace oven from Heraeus Instruments (Hanau, Germany) to calcinate and activate the solid catalytic samples; a centrifugation equipment, HERMLE-Z 300 (Labnet International, Inc., Edison, NJ, USA), to separate 
the produced soaps in the neutralization process of free fatty acids (FFA) in waste cooking oils (WCO); a heating plate with a magnetic stirrer from LBX (Labbox Labware, Barcelona, Spain) for drying biodiesel liquid samples; an FTIR-ATR (Fourier-Transform Infrared Spectroscopy-Attenuated Total Reflection) spectrometer, model Interspec 200-X, from Interspectrum OU (Tartumaa, Estonia) to plot the FTIR spectra of the solid and liquid samples; a refractometer, D'Abbé, from ATAGO (Tokyo, Japan) to quantify the FAME content of biodiesel samples produced in order to evaluate their purity; and finally, a $\mathrm{pH} /$ conductivity meter, AD8000, from ADWA (Szeged, Hungary) to measure the $\mathrm{pH}$ of washing waters in the biodiesel purification process.

\subsection{Preparation of Natural $\mathrm{CaO}$ Catalysts}

The catalyst was prepared from natural sources of $\mathrm{CaCO}_{3}$. Six different calcium-rich waste components were used for the catalyst mixture. The components that made up the catalyst were eggshells, shrimp shells, crab shells, "navalha" shells, and dark-colored and white-colored seashells (clams). Shells were collected from the Lisbon beaches to prepare the Ca-based "shell mix" catalyst. The collected shells were washed and left overnight in an oven (for around $15 \mathrm{~h}$ ), which was set to $110{ }^{\circ} \mathrm{C}$ to perform the drying process. After drying, manual grinding was completed in an agate mortar, to obtain fine powder materials. Subsequently, certain amounts of catalyst components were taken from each component and the pre-calcination process was carried out in a furnace oven at $300{ }^{\circ} \mathrm{C}$ for $3 \mathrm{~h}$. After that, FTIR-ATR analysis was performed for each calcium waste material. In order to perform the calcination process, the same catalyst mixture (shell mix) was prepared through calcination at $850{ }^{\circ} \mathrm{C}$ in the same furnace oven, for $3 \mathrm{~h}$. The aim was to remove the moisture and carbon dioxide contained in the catalyst mixture and convert calcium carbonate $\left(\mathrm{CaCO}_{3}\right)$ into calcium oxide $(\mathrm{CaO})$. Thus, the catalyst was activated. At the end of the process, the catalyst contained in the ceramic capsule was taken to a desiccator for cooling.

\subsection{Waste Cooking Oil Pre-Treatment}

The waste cooking oils (WCO) were collected from the university canteen of ISEL (Instituto Superior de Engenharia de Lisboa), and their quality was improved through several purification steps, including drying, washing, centrifugation and neutralization. First, the WCO samples were filtered under vacuum filtration, distributed to specifically remove some immiscible solid particles, and then dried at $110^{\circ} \mathrm{C}$ for $90 \mathrm{~min}$ to remove some humidity content. Then, the samples were placed in a heating bath at $45^{\circ} \mathrm{C}$ for $15 \mathrm{~min}$ under mechanical stirring and at this time, approximately $0.05 \mathrm{~g}$ of $85 \%$ $(w / w)$ of phosphoric acid was added to each $100 \mathrm{~g}$ of WCO. After this step, the acidity index (AI) was calculated and since the calculated value was found to be higher than $0.5 \mathrm{mg} \mathrm{KOH} / \mathrm{g}$ oil, a neutralization process was performed with $8 \%(w / w)$ of an aqueous solution of sodium hydroxide $(\mathrm{NaOH})$ at $45^{\circ} \mathrm{C}$ for $30 \mathrm{~min}$, until an AI value below $0.5 \mathrm{mg} \mathrm{KOH} / \mathrm{g}$ oil was reached. After the neutralization process, the WCO samples were placed in a centrifugation equipment, to separate the soaps produced during the neutralization reaction, at $4000 \mathrm{rpm}$ for $10 \mathrm{~min}$. Then, several washing steps were performed with a citric acid aqueous solution and hot demineralized water in a decantation funnel to remove remaining contents of $\mathrm{NaOH}$ and some soluble impurities in the WCO samples as well as remaining contents of citric acid from the previous washings. Finally, the WCO samples were dried at $120^{\circ} \mathrm{C}$ for $2 \mathrm{~h}$. At this stage, the WCO samples were prepared for performing the transesterification reaction process.

\subsection{Transesterification Reaction Process}

The transesterification reaction procedure with the heterogenous catalyst was performed as follows: A $500 \mathrm{~mL}$ triple-necked flask was used as a reactor for the transesterification process. A double blade mixer apparatus was placed inside the flask and mounted on the mechanical stirrers. A cooler was used to prevent the evaporation of methanol during the reaction and it was connected to one of the reactor inlets (reflux apparatus). The set-point temperature of the water bath was set in order to achieve $60^{\circ} \mathrm{C}$ inside the reactor. When the desired temperature was reached, methanol and WCO at a 
molar ratio of $12: 1$ and $5 \%\left(\mathrm{~W}_{\text {cat. }} / \mathrm{W}_{\mathrm{WCO}}\right)$ were prepared and added to the reactor. Then, a purified WCO sample, previously heated at $60{ }^{\circ} \mathrm{C}$ with the help of a heating plate, was added to the reactor and the reaction was started. Different reaction times were studied and $6 \mathrm{~h}$ was found to be enough as the reaction time. After changing the composition of the catalyst, according to the transesterification reaction results, $2 \mathrm{~h}$ was considered as the optimum reaction time. At the end of the transesterification process, the catalyst was collected on a filter paper under vacuum filtration and separated from the final liquid product, which was settled in a decantation funnel to separate the two immiscible phases: the upper one with fatty acid methyl esters (FAME-biodiesel) and the lower one with glycerin (glycerol plus unreacted methanol).

A homogeneous process was used to benchmark the heterogeneous process, and it was performed with the same operational procedure, but with the following operating conditions: $60^{\circ} \mathrm{C}, 2 \mathrm{~h}$ of reaction time, a methanol/WCO molar ratio equal to 6 , and $0.6 \%(w / w)$ of sodium hydroxide catalyst solubilized in methanol, related to WCO. Table 1 shows the comparison between the operating conditions used in the heterogeneous and homogeneous processes.

Table 1. Comparison between the operating values used in both heterogeneous and homogeneous catalyzed processes.

\begin{tabular}{ccc}
\hline Element & Heterogeneous Process & Homogeneous Process \\
\hline $\mathrm{T}\left({ }^{\circ} \mathrm{C}\right)$ & 60 & 60 \\
$\mathrm{t}(\mathrm{h})$ & 2 & 2 \\
$\mathrm{MeOH} / \mathrm{WCO}$ molar ratio & 12 & 6 \\
Catalyst & Shell mix $(\mathrm{CaO}), \mathrm{c} .850{ }^{\circ} \mathrm{C}$ & $\mathrm{NaOH}$ with methanol \\
$\%\left(\mathrm{~W}_{\text {cat. }} / \mathrm{W}_{\mathrm{WCO}}\right)$ & $5.0 \%$ & $0.6 \%$ \\
\hline
\end{tabular}

\subsection{Biodiesel Purification Process}

After the separation of biodiesel and glycerin phases, the produced biodiesel was washed three consecutive times: the first time with demineralized water to remove non-reacted methanol and other contaminants, the second time with $1.5 \%(w / w)$ aqueous nitric acid solution to remove the remaining contents of the catalyst, and the last time with demineralized water to remove the remaining contents of nitric acid from the previous washing step. After that a centrifugation step was performed and finally, biodiesel was dried in a heating plate at $110^{\circ} \mathrm{C}$ for $40 \mathrm{~min}$.

\section{Results and Discussion}

\subsection{Catalyst Characterization}

Catalyst characterization was performed on natural calcium waste materials, essentially through SEM-EDS (scanning electronic microscopy with electron diffraction spectroscopy), for morphological characterization; XRD (X-ray diffraction) for structural characterization and identification of crystalline phases; and $\mathrm{N}_{2}$ adsorption at $77 \mathrm{~K}$ for textural characterization to quantify solid specific area. Finally, semi-quantification of catalyst basicity was also performed through the utilization of a Hammett indicator.

Regarding morphological characterization, Figure 2 shows, from left to the right, SEM images of the shell mix new composition heterogeneous catalyst, respectively, before calcination (A), after calcination (B), and after first batch transesterification reaction step (C). All images were acquired at $8000 \times$ magnification. 

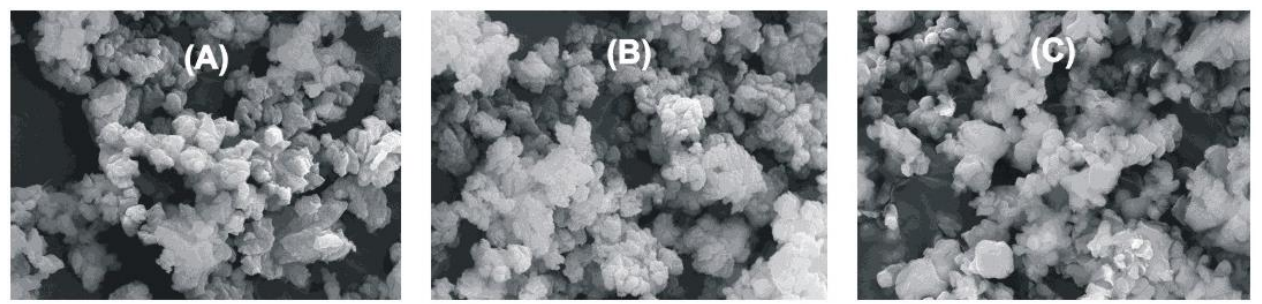

Figure 2. SEM images $(5000 \times, 1 \mu \mathrm{m})$ of shell mix solid catalyst, (a) before calcination, (b) after calcination, and (c) after the first transesterification step.

These images were almost similar to the $\mathrm{CaO}$ catalyst images reported in several works, such as [37]. Table 2 shows the atomic composition of the shell mix catalyst from situations A, B, and C, collected through the EDS technique.

Table 2. Atomic compositions (\%) of shell mix ("Shellm.") collected through EDS (Energy Dispersive Spectroscopy).

\begin{tabular}{cccc}
\hline Element & $\begin{array}{c}\text { "Shellm." before } \\
\text { Calcination }\end{array}$ & $\begin{array}{c}\text { "Shellm." after } \\
\text { Calcination }\end{array}$ & $\begin{array}{c}\text { "Shellm." after First } \\
\text { Reaction }\end{array}$ \\
\hline $\mathrm{C}$ & $21.6 \pm 1.0 \%$ & $4.39 \pm 1.1 \%$ & $8.1 \pm 1.0 \%$ \\
$\mathrm{O}$ & $59.3 \pm 1.3 \%$ & $59.9 \pm 1.1 \%$ & $63.5 \pm 1.2 \%$ \\
$\mathrm{Ca}$ & $19.1 \pm 0.9 \%$ & $35.7 \pm 1.0 \%$ & $28.4 \pm 1.1 \%$ \\
\hline
\end{tabular}

Note: average values collected from three different catalyst surface measurements.

The significant decrease in carbon composition after calcination is due to the conversion of calcium carbonate to calcium oxide, which is to be expected, since this decomposition process of calcium carbonate is well known to occur between $800-900^{\circ} \mathrm{C}$. As a consequence, calcium composition increases proportionally. On the other hand, carbon composition slightly increases, due to the adsorption of oily species during the transesterification reaction, as reported in Section 3.3, covering progressively, the available active sites of the catalyst surface. Also, the noticed decrease in calcium content, after the first reaction is probably due to leaching of this element, as noticed previously in other studies [19].

Regarding catalyst crystallinity, Figure 3 shows diffractograms of the shell mix calcinated at $850^{\circ} \mathrm{C}$, before (a) and after (b) the first batch transesterification step. The differences in both diffractograms are related to the diffraction lines pointed out in diffractogram (b), ascribable to calcite (calcium carbonate), while the remaining diffraction lines are common in both diffractograms, ascribable to lime (calcium oxide). This fact seems to be related to the transformation of some of the calcium oxide particle catalyst into calcium carbonate, due to the contact of the calcium oxide catalyst with the reaction organic species. As mentioned before, calcium oxide is strongly hygroscopic and a strong $\mathrm{CO}_{2}$ adsorber. It is also possible to notice the crystalline phases of the calcinated shell mix catalyst. 


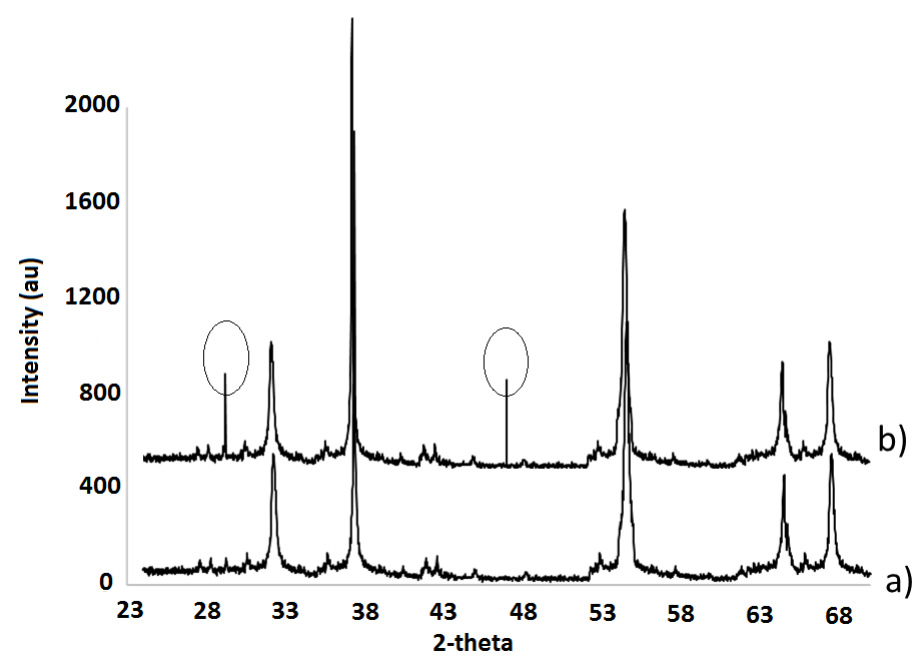

Figure 3. XRD diffractograms of the shell mix solid catalyst before (a) and after (b) the first reaction step.

An $\mathrm{N}_{2}$ adsorption technique was applied for shell mix textural characterization at $77 \mathrm{~K}$ and the Brunauer-Emmett-Teller (BET) isothermal model was applied to estimate the specific area of the solid mixture. Figure 4 shows adsorption/desorption isothermal lines applied for the shell mix catalyst, after the calcination process. Through the BET model, the specific area calculated for the shell mix was equal to $2.93 \mathrm{~m}^{2} \cdot \mathrm{g}^{-1}$, which corresponds to a macro porous solid due to its lower value of specific area. Besides, other researchers like [38] reported a value of $4.6 \mathrm{~m}^{2} \cdot \mathrm{g}^{-1}$, which is a very close value, confirming these results. Several researchers pointed out that the calcium oxide catalyst is very active in transesterification reactions, mainly at the surface, due also to its lower value of specific area and higher value of porous volume $[37,39,40]$.

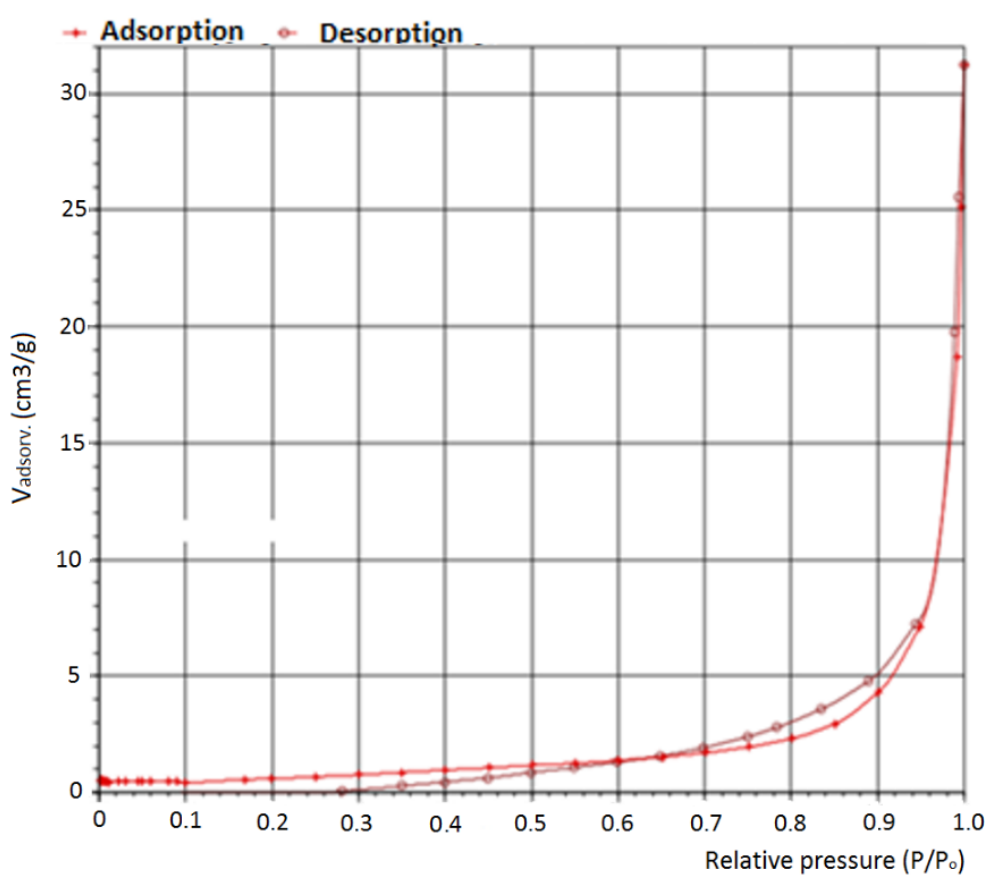

Figure 4. Adsorption and desorption isothermals of the shell mix catalyst after calcination.

The $\mathrm{N}_{2}$ adsorption/desorption diagram of a fresh catalyst is almost the same as the one illustrated in Figure 4, with a little difference in the specific area, as the solid catalyst is characterized by a macro porous structure with a significant lower surface area, so it is not expectable to notice significative differences before and after the calcination process in these diagrams. 
Figure 5 shows granulometric lines, accessed by diffraction laser-beam scattering (DLS) using methanol as a wet fluid to drag all the sample particles, representing the number of particles (\%) depending on the diameter $(\mu \mathrm{m})$ of shell mix catalyst particles before and after the transesterification reaction. It is possible to conclude that, after the reaction process, a significant number of particles with a higher diameter (e.g., $2 \mu \mathrm{m}$ ) were subjected to reduction of granulometry and converted, for instance, to $1 \mu \mathrm{m}$ diameter. This behavior is probably due to the continuous stirring in the reactor, which causes defragmentation on the heterogeneous (solid) catalyst particles when they come into contact with the reactants' liquid phase and also due to the shovels of the mechanical stirrer, which is under a continuous rotational speed.

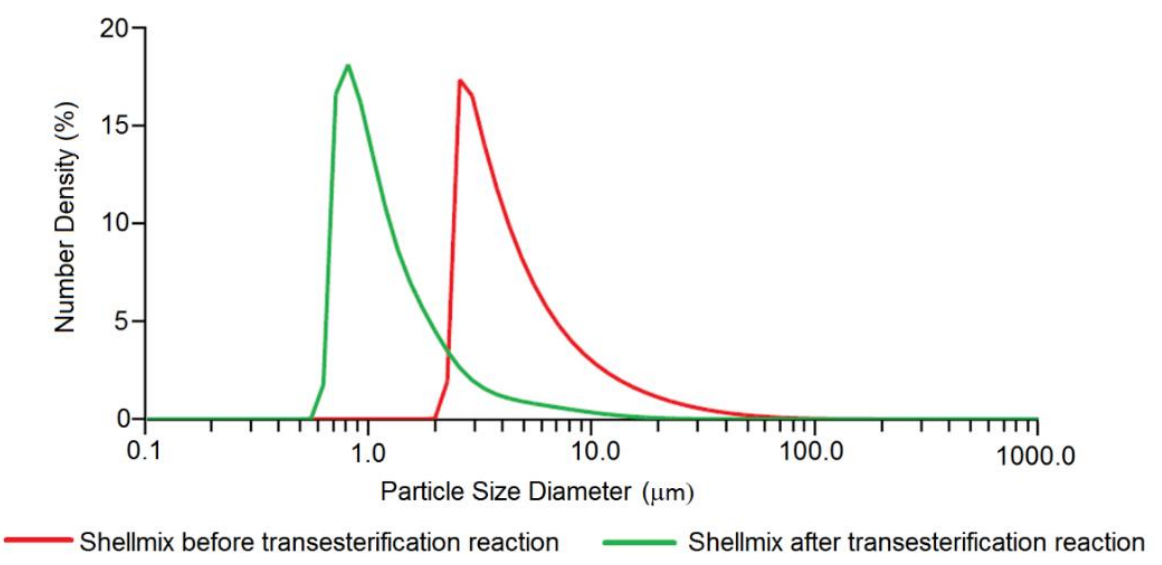

Figure 5. DLS (Dynamic Light Scattering) granulometric lines of the shell mix catalyst before and after the transesterification reaction.

Finally, a few drops of a methanolic solution of 4-chlorine-2-nitroaniline ( $\mathrm{pKa}=18.2)$ were used as the Hammett indicator on the shell mix solid catalyst's surface to identify its basicity. This indicator shows a yellow color in the liquid phase and also shows this same color on the catalyst surface, after deposition of the drops. After a certain time, any color change observed on the catalyst surface indicates that the catalyst is strongly alkaline with $\mathrm{pKa}>18.2$. It checks its basicity behavior, due to its alkaline active sites [41]. Figure 6 [41] shows a typical scheme of a metallic oxide, such as calcium oxide, the most important component of the shell mix catalyst, where it is possible to identify the acid $(\delta+)$ and alkaline $(\delta-)$ active sites.

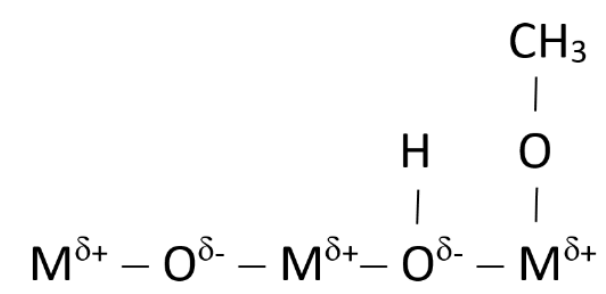

Figure 6. Typical metallic oxide surface with the corresponding active sites' distribution [41].

\subsection{Biodiesel Characterization}

After the transesterification and separation-purification processes, the biodiesel obtained was analyzed by FTIR-ATR (Fourier-transform infrared spectroscopy) to identify the absorption peaks and compare them with the absorption peaks for homogeneously synthesized biodiesel and treated WCO (Figure 7). The homogeneous synthesis method is used as a reference for biodiesel production, in order to compare it with the heterogeneous process. The ellipse marks identified the FAME absorption peaks, which were present in the biodiesel samples, but not in the WCO samples. The biodiesel heterogeneous samples were compared with the homogeneous sample (a standard for comparison) obtained using the 
same reaction apparatus at $60{ }^{\circ} \mathrm{C}$, but with a methanol: WCO molar ratio of $6: 1$ and $0.6 \%\left(\mathrm{~W}_{\text {cat. }} / \mathrm{W}_{\text {oil }}\right)$ for $2 \mathrm{~h}$, and the same purification process.

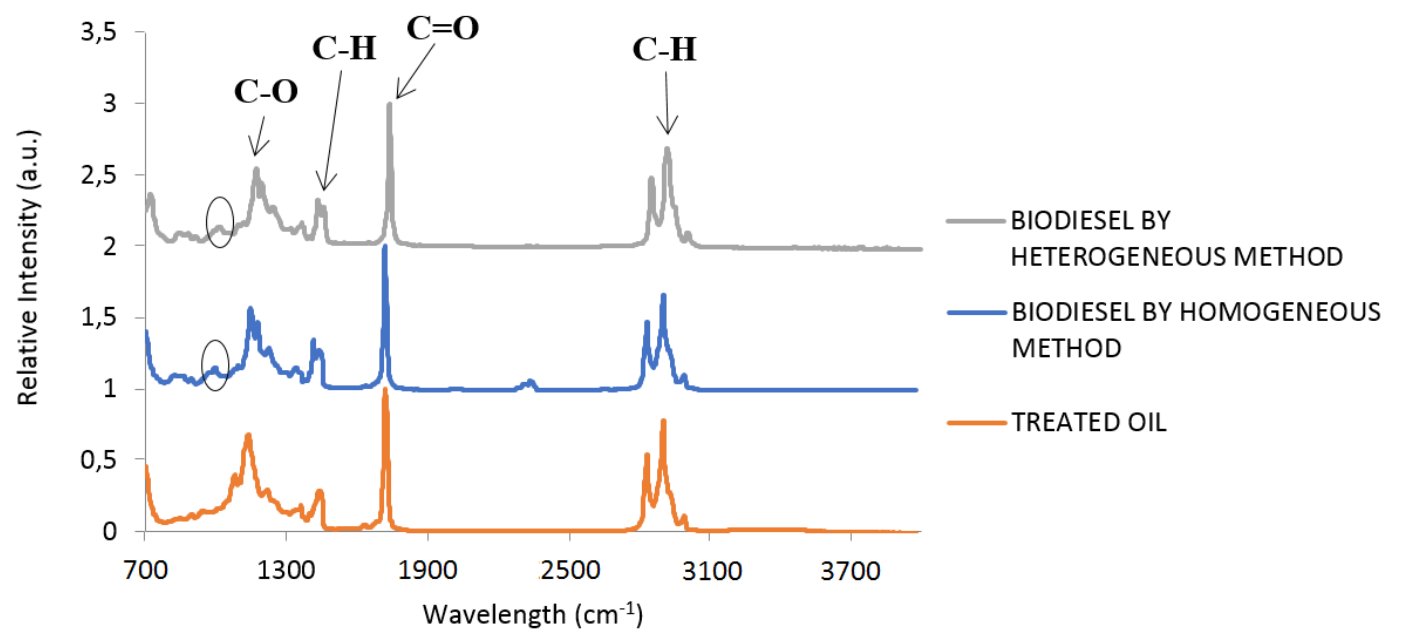

Figure 7. FTIR-ATR results for biodiesel and treated WCO (Waste Cooking Oil).

The catalyst used in the homogeneous process is, typically, sodium hydroxide solubilized in methanol. Results showed that the FTIR spectra of biodiesel homogeneous and heterogeneous samples were identical.

The composition of methyl esters in oils and in the produced biodiesel was determined by refractometry to quantify the FAME (\%) weight content, which is directly related to biodiesel purity and biodiesel yield. Since soap formation was not observed in the liquid samples, it indicates that there are practically no side reactions and the FAME yield is practically equal to the transesterification conversion rate. A calibration curve was previously performed on the refractive index through the FAME (\%) content, by using several standards of biodiesel in WCO $\left(0,20,40,60,80\right.$, and $100 \%$ ( $\left.\mathrm{W}_{\text {biod. }} / \mathrm{W}_{\mathrm{WCO}}\right)$ ). The obtained FAME yield results are presented in Table 3 and they showed that the calcined shell mixture of all the components initially yielded at the end of $8 \mathrm{~h}$ reaction time. However, considering that this is not very practical, all components were calcined again at $850^{\circ} \mathrm{C}$ for $3 \mathrm{~h}$ in an oven and then the transesterification reaction was performed. The obtained FAME contents were then interpreted and it was concluded that the FAME percentage of white-colored clams was somewhat low. In contrast, shrimp shell, dark-colored clam, and "navalha" shell seafood wastes showed FAME yields higher than $99.5 \%$, which is a very interesting result. However, in a previous study [37], it was reported that $\mathrm{CaO}$ reacted with glycerol after transesterification of soybean oil with methanol and calcium diglyceroxide was formed in the glycerin phase. Therefore, an extra purification step, for example with an ion-exchange resin, is needed to remove the soluble content in the biodiesel. Thus, in this study, egg shells may tend to react with glycerol immediately after transesterification due to its rich $\mathrm{CaO}$ content and form the same structure. Initially $20 \mathrm{~g}$ of each component ( $20 \%$ for each one) was used to prepare the shell mix mixture before performing the transesterification reaction for each component separately. In light of all these results, the composition, by weight, of the new shell mix mixture was changed and egg shells were removed.

The new shell mix composition, by weight, comprised of $16.7 \%$ of white-colored clams, $25.0 \%$ of dark-colored clams and crab shells, $25.0 \%$ of "navalha" shells, and $33.3 \%$ of shrimp shells. In light of the results obtained, $5 \%\left(\mathrm{~W}_{\text {cat. }} / \mathrm{W}_{\mathrm{oil}}\right)$, methanol: $\mathrm{WCO}$ at a molar ratio of $12: 1,60^{\circ} \mathrm{C}$ working temperature, and $6 \mathrm{~h}$ of reaction time were considered to constitute the optimized method after performing the "repeatability test". 
Table 3. FAME (Free Acid Methyl Ester) contents for biodiesel samples obtained under different conditions.

\begin{tabular}{|c|c|c|c|}
\hline Type of Catalyst & Reaction Time (h) & Refractive Index, $25^{\circ} \mathrm{C}$ & FAME Conversion ( $\%)$ \\
\hline \multirow{7}{*}{$\begin{array}{l}\text { Shell mix (former } \\
\text { composition) }\end{array}$} & 4 & 1.47735 & 1.10 \\
\hline & 5 & 1.47731 & 1.20 \\
\hline & 6 & 1.47729 & 1.30 \\
\hline & $\begin{array}{c}5 \\
\text { (separately calcinated) }\end{array}$ & 1.46709 & 49.9 \\
\hline & $\begin{array}{c}2 \\
\text { (Methanol + catalyst, } 3 \text { h) }\end{array}$ & 1.47733 & 1.20 \\
\hline & $\begin{array}{c}1 \\
\text { (Methanol }+ \text { catalyst, } 7 \text { h) } \\
1\end{array}$ & 1.45669 & $>99.5$ \\
\hline & $\underset{\text { (a) }}{(\text { Methanol }+ \text { catalyst, } 3 \mathrm{~h})}$ & 1.47725 & 1.80 \\
\hline White-colored clam & 6 & 1.46700 & 50.0 \\
\hline Shrimp shell & 6 & 1.45665 & $>99.5$ \\
\hline "Navalha" shell & 6 & 1.45663 & $>99.5$ \\
\hline \multirow[t]{2}{*}{ Dark-colored clam } & 6 & 1.45662 & $>99.5$ \\
\hline & 5 & 1.47730 & 1.20 \\
\hline \multirow[t]{3}{*}{$\mathrm{Ca}(\mathrm{OMe})_{2}$} & 7 & 1.46716 & 50.8 \\
\hline & 8 & 1.45661 & $>99.5$ \\
\hline & 5 & 1.47727 & 1.40 \\
\hline \multirow[t]{2}{*}{$\mathrm{Ca}(\mathrm{OH})_{2}$} & 7 & 1.47726 & 1.40 \\
\hline & 8 & 1.45661 & $>99.5$ \\
\hline Glycerol + Methanol ${ }^{(b)}$ & 2 & 1.45662 & $>99.5$ \\
\hline Shell mix $5 \%(w / w)^{(\mathrm{c})}$ & 6 & 1.45662 & $>99.5$ \\
\hline Shell mix 3\%(w/w) ${ }^{(c)}$ & 6 & 1.46690 & 50.4 \\
\hline
\end{tabular}

(a) With acetone as co-solvent; ${ }^{(b)}$ co-production of calcium diglyceroxide; ${ }^{(c)}$ new shell mix without eggshell added. The replication measurements were only applied for those samples which showed a FAME content higher than $96.5 \%(w / w)$ (minimum value for standard quality biodiesel, according to the EN 14214 standard). In all cases, the replication shows values of FAME content higher than $99.5 \%$.

\subsection{Biodiesel Repeatability Test}

After determining the most appropriate methods and conditions for biodiesel synthesis, the repeatability test was performed five times to ensure accuracy. As mentioned earlier, the same working conditions were adopted, e.g., the transesterification reaction was carried out for $6 \mathrm{~h}$ in a triple-necked flask using a mechanical stirrer with $5 \%\left(\mathrm{~W}_{\text {cat. }} / \mathrm{W}_{\mathrm{WCO}}\right)$ and 12:1 molar methanol: WCO ratio at $60^{\circ} \mathrm{C}$ in a heated water bath (reflux apparatus), for the new shell mix composition. Repeatability test results are shown in Table 4.

Table 4. Repeatability test results for biodiesel product.

\begin{tabular}{cc}
\hline Number of Experiment $(\#)$ & FAME Yield $\left(\mathbf{\%} \mathbf{W}_{\text {biod. }} / \mathbf{W}_{\mathbf{W C O}}\right)$ \\
\hline$\# 1$ & 99.9 \\
$\# 2$ & 99.8 \\
$\# 3$ & 99.9 \\
$\# 4$ & 99.7 \\
$\# 5$ & 99.8 \\
\hline
\end{tabular}

Regarding Table 4 results, the average value achieved was $99.82 \%$ of FAME content and the standard deviation value calculated was $0.08 \%$.

\subsection{Catalytic Stability Test}

Catalytic stability tests were performed to evaluate the suitability and stability of the catalyst after the first transesterification reaction (first catalytic cycle). All environment and working conditions 
were maintained for the transesterification reaction, e.g., tests were performed for $2 \mathrm{~h}$ only instead of $6 \mathrm{~h}$. This change was based on kinetic test results. The catalyst, between stages, after separation of the liquid phase through vacuum filtration, was only dried overnight on a filter paper in an oven set to $90^{\circ} \mathrm{C}$. Table 5 presents the FAME content (\% $\mathrm{W}_{\text {biod. }} / \mathrm{W}_{\mathrm{WCO}}$ ) in the catalytic stability tests.

Table 5. FAME yield (\%) of biodiesel products obtained as a result of catalytic stability tests.

\begin{tabular}{cc}
\hline Number of Experiment $(\#)$ & FAME Yield $\left(\mathbf{\%} \mathbf{W}_{\mathbf{b i o d} .} / \mathbf{W}_{\mathbf{W C O}}\right)$ \\
\hline$\# 1$ & $99.9 \pm 1.0 \%$ \\
$\# 2$ & $99.9 \pm 1.2 \%$ \\
$\# 3$ & $99.8 \pm 0.9 \%$ \\
$\# 4$ & $28.9 \pm 2.2 \%$ \\
\hline
\end{tabular}

As a result of these tests, it was observed that the shell mixture ("shell mix") used as the heterogeneous catalyst was suitable for use three times consecutively, which is quite an interesting result. As in another study in the literature [6], the same catalyst could be used three consecutive times with a high FAME conversion rate. The catalyst had a limited life to be reused, as seen before. In this study, it was found that the catalyst can be used three times consecutively without losing its higher activity. The reason for the significant FAME content drop from the fourth batch reaction and consequently, a decrease in the shell mix catalytic activity, is the decreasing number of catalyst active sites due to progressive adsorption of oil/methyl ester molecules on the surface of the catalyst, covering the mentioned active sites and deactivating the catalyst. For instance, the causes of deactivation for pure $\mathrm{CaO}$ catalyst derived from renewable resources were as follows [5]: $\mathrm{CO}_{2}$ and $\mathrm{H}_{2} \mathrm{O}$ existed in air and reactants, adsorbed onto the catalyst surface, poisoned it $(\mathrm{CaO}$ is highly hygroscopic and easily adsorbs $\mathrm{CO}_{2}$ ), and converted $\mathrm{CaO}$ into $\mathrm{Ca}(\mathrm{OH})_{2}$ and $\mathrm{CaCO}_{3}$, respectively; the co-production of calcium diglyceroxide on the catalyst surface during reaction, which results from the interaction between $\mathrm{CaO}$ and glycerol; and the leaching of $\mathrm{Ca}^{2+}$ ions from the $\mathrm{CaO}$ surface, since calcium diglyceroxide is soluble in glycerin phase. Nevertheless, the catalyst can be reactivated easily, if recalcination is applied, as reported by several researchers, to desorb the oily species as well as previously adsorbed $\mathrm{CO}_{2}$ and $\mathrm{H}_{2} \mathrm{O}$. However, it is important to avoid a significant formation of calcium diglyceroxide, otherwise, a catalyst weight loss with the time reaction will take place, thus leading to a significant increase in operating costs [37]. Figure 8 shows FTIR-ATR spectra of the liquid biodiesel samples obtained from the catalytic stability tests.

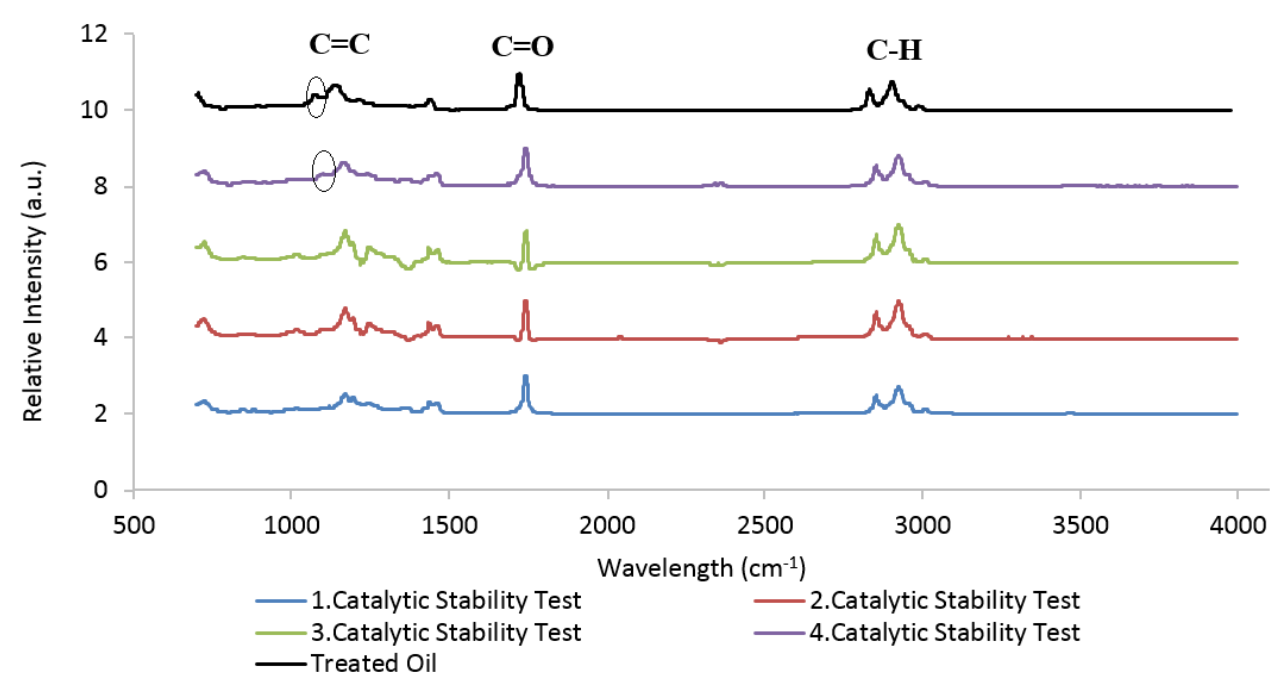

Figure 8. Comparison of FTIR-ATR results of biodiesel samples produced by catalytic stability tests and treated waste cooking oils (WCO). 


\subsection{Kinetic Tests}

In order to evaluate time dependency, kinetic tests were performed for the new composition of the shell mix solid catalyst for different reaction times up to $6 \mathrm{~h}$, at $60^{\circ} \mathrm{C}$ with a methanol/WCO molar ratio of 12 and $5 \%$ of $\left(\mathrm{W}_{\text {cat. }} / \mathrm{W}_{\mathrm{WCO}}\right)$. The purpose was also to estimate apparent constant kinetic rates at $60{ }^{\circ} \mathrm{C}$ by using the shell mix heterogeneous catalyst. Table 6 and Figure 9 show FAME yield time dependency. After that, the apparent constant velocity $(\mathrm{k})$ at $60^{\circ} \mathrm{C}$ of the transesterification process was estimated for the operatory conditions mentioned in Section 2.5 (Table 1) and with the heterogeneous catalyst samples, depending on whether the reaction kinetic order law is of the 1st order or 2nd order. The best correlation coefficient $\left(\mathrm{R}^{2}\right)$ will lead to the corresponding transesterification kinetic equation. The molar ratio of methanol/WCO used corresponds to a significant excess quantity of alcohol $(300 \%)$, since the stoichiometry methanol/WCO molar ratio is only equal to 3 , which means that for each mol of WCO (triglyceride molecule), 3 mol of methanol will be needed in order to produce 3 mol of methyl esters (biodiesel) and $1 \mathrm{~mol}$ of glycerol as the co-product. This significant excess of methanol ensures that the only limiting reactant will be WCO, since in this situation, for each mol of triglyceride, $12 \mathrm{~mol}$ of methanol were applied, instead of the necessary (stoichiometric) 3 mol.

Table 6. Kinetic test results for different reaction times.

\begin{tabular}{cc}
\hline Reaction Time (min.) & FAME Yield $\left.\mathbf{( \%} \mathbf{W}_{\text {biod. }} / \mathbf{W}_{\mathbf{W C O}}\right)$ \\
\hline 0 & 0.00 \\
30 & 1.30 \\
45 & 1.50 \\
60 & 1.80 \\
75 & 24.8 \\
80 & 25.0 \\
90 & 99.7 \\
120 & 99.8 \\
180 & 99.8 \\
240 & 99.8 \\
300 & 99.9 \\
360 & 99.9 \\
\hline
\end{tabular}

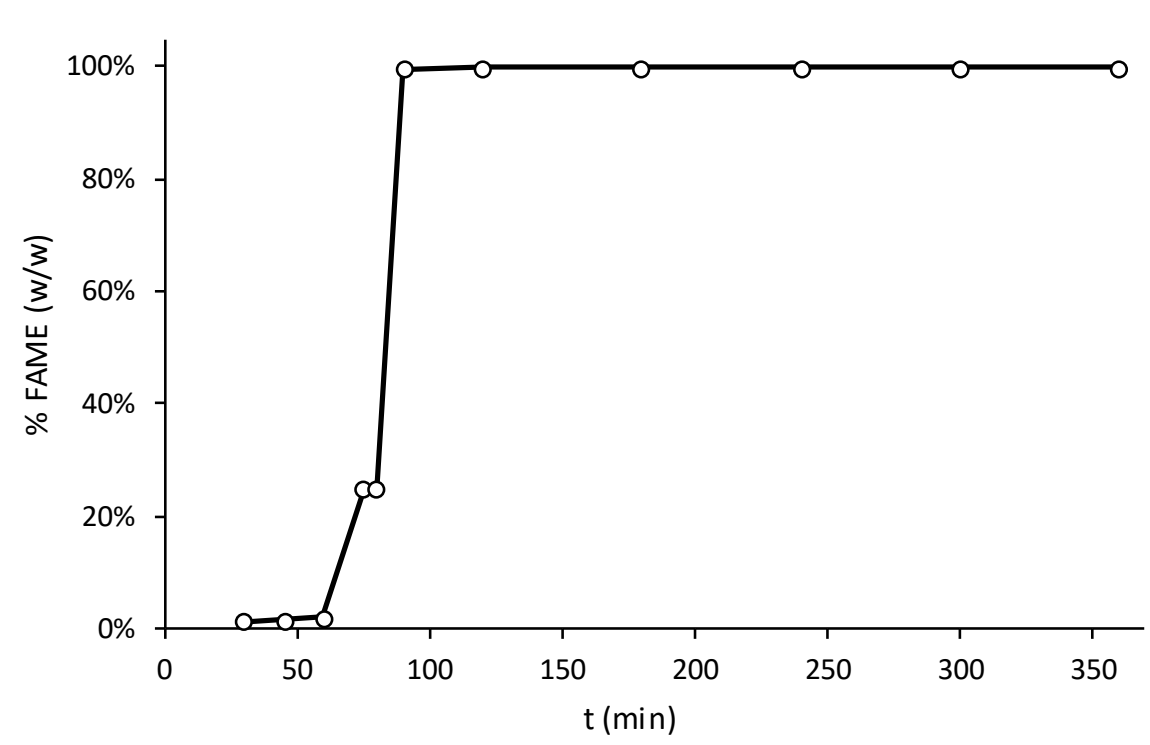

Figure 9. Kinetic test results for different reaction times.

The transesterification reaction is the result of three consecutive equilibrium reaction steps as follows: 1st step is the conversion of triglyceride (TG) molecules into diglyceride (DG) molecules; in the 2nd step, these diglycerides are converted into monoglyceride (MG) molecules; and finally, 
in the 3rd step, the monoglycerides are converted into glycerol (G). In each equilibrium step, $1 \mathrm{~mol}$ of methanol (M) is used and it will produce $1 \mathrm{~mol}$ of methyl ester (ME) in each step. The significant excess of methanol (300\%) leads all the three equilibrium reaction steps into the direction of chemical production of reaction products, thus enhancing biodiesel production and WCO conversion, according to the Le Chatelier postulate.

1st step:

$$
\mathrm{TG}+\mathrm{M} \leftrightarrow \mathrm{ME}+\mathrm{DG}
$$

2nd step:

$$
\mathrm{DG}+\mathrm{M} \leftrightarrow \mathrm{ME}+\mathrm{MG}
$$

3rd step:

$$
\mathrm{MG}+\mathrm{M} \leftrightarrow \mathrm{ME}+\mathrm{G} .
$$

The overall reaction is given by:

$$
\mathrm{TG}+3 \mathrm{M} \leftrightarrow 3 \mathrm{ME}+\mathrm{G} .
$$

An excess of methanol will also tend to minimize mass transfer external diffusion limitations between reactants' liquid phase and catalyst surface. Regarding mass transfer internal diffusion limitations, it was assumed that there are very few mass transfer internal diffusion limitations in this process since the catalyst is a macro porous structure and the pores have a higher diameter, thus leading to a lower surface area $\left(<5 \mathrm{~m}^{2} \cdot \mathrm{g}^{-1}\right)$ as mentioned before.

Those were the assumptions to define the present kinetic model, assuming pseudo-first order kinetic law, due also to the mentioned mass transfer diffusion limitations, typically occurring in heterogeneous catalysis.

From Figure 9, it is possible to conclude that there are some mass transfer limitations due to time delay in the transesterification reaction, since only after $1 \mathrm{~h}$, a significant increase in FAME yield took place, when the reaction started. The rapid increase in FAME yield over time, resulted in achieving values higher than $99 \%$ at the end of only 30 min, leading to the conclusion that the reaction step is very fast and the kinetic limiting step is probably related to the mass transfer external diffusion limitations.

After performing the linearization of 1 st and 2 nd kinetic order equations, $\left(-\mathrm{dC} \mathrm{oil}_{\mathrm{oil}} / \mathrm{dt}=\mathrm{k} \cdot\left(\mathrm{C}_{\mathrm{oil}}\right)\right.$ and $-\mathrm{dC}_{\mathrm{oil}} / \mathrm{dt}=\mathrm{k} \cdot\left(\mathrm{C}_{\mathrm{oil}}\right)^{2}$, respectively, where $\mathrm{dC}_{\mathrm{oil}}$ is the limiting concentration of the WCO over time $(\mathrm{dt})$ and $\mathrm{k}$ is the apparent kinetic rate constant), the best correlation coefficient was achieved with the linearization of the 1st kinetic order equation, thus leading to the following kinetic equation:

$$
-\frac{\mathrm{dC}_{\mathrm{wCO}}}{\mathrm{dt}}=0.0036 \cdot \mathrm{C}_{\mathrm{WCO}}
$$

where the achieved value of $\mathrm{k}$ was found to be equal to $3.6 \times 10^{-3} \mathrm{~min}^{-1}$. Figure 10 shows FTIR-ATR spectra of some collected shell mix catalysts after the kinetic transesterification test. Results showed that, with time, oily species will adsorb onto the surface catalyst, since absorption peaks for the $\mathrm{C}-\mathrm{H}$ and $\mathrm{C}-\mathrm{O}$ bonds of esters were identified. The carbonate group, resulting from the progressive adsorption of $\mathrm{CO}_{2}$ molecules and which reacts with calcium oxide to produce calcium carbonate, was also identified. 


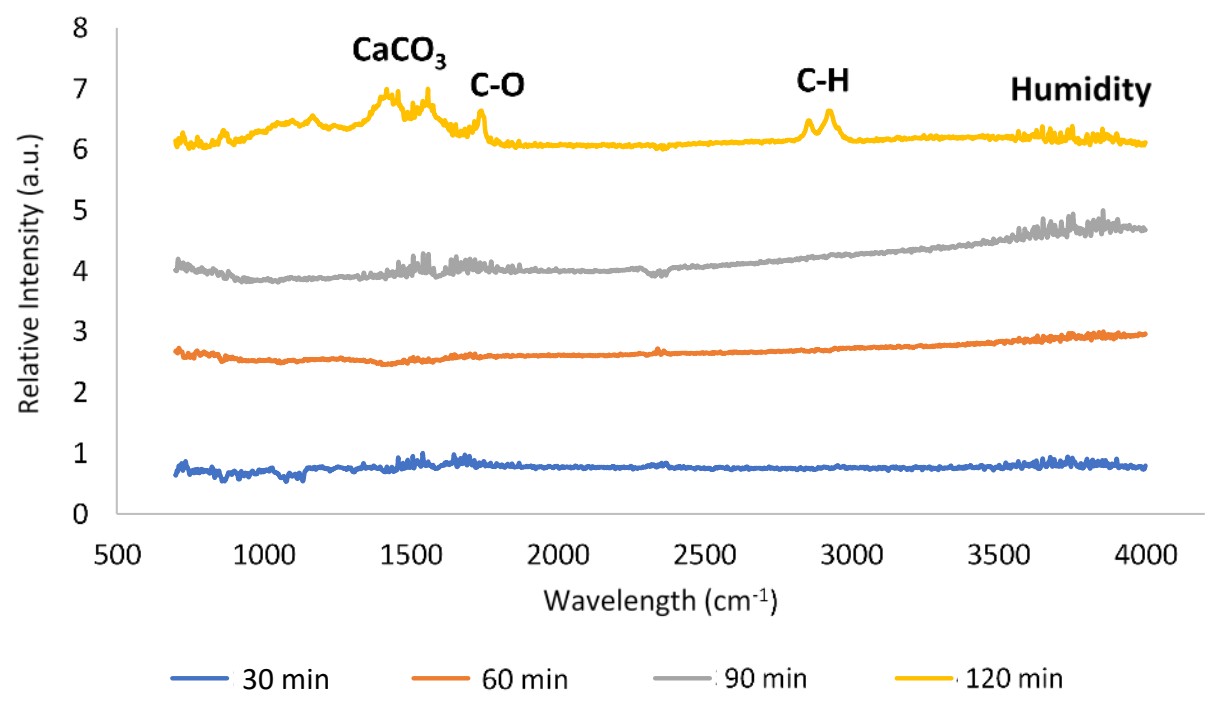

Figure 10. FTIR-ATR results of shell mix catalyst samples dried after kinetic tests.

\subsection{Determination of Physical Properties of Produced Biodiesel}

The physical properties of the obtained biodiesel product such as kinematic viscosity at $40{ }^{\circ} \mathrm{C}$, density, and acidity index, besides FAME content (\%), were determined and compared with the European standard EN 14214. To quantify the acidity index of the biodiesel samples, $0.1 \mathrm{M}$ of $\mathrm{KOH}$ ethanolic solution was prepared as the titration agent through an acid-base titration. Biodiesel samples produced from the catalytic stability tests were used. The biodiesel samples were solubilized in a small volume of acetone and titrated with the $\mathrm{KOH}$ solution. After titration, a pink-violet color change was observed due to the presence of phenolphthalein indicator. The analysis method performed was exactly the same method used to quantify the acidity index (AI) in the WCO samples, before the neutralization process. The results are listed in Table 6 . The expression for calculating the acidity index values is:

$$
\mathrm{AI}(\mathrm{mg} \mathrm{KOH} / \mathrm{g} \text { oil })=\left(\frac{56.11 \times 0.1 \times \mathrm{V}_{\mathrm{KOH}}}{\mathrm{m}_{\mathrm{WCO}}}\right),
$$

where $\mathrm{V}(\mathrm{KOH})$ is the volume of $\mathrm{KOH}$ necessary to titrate the WCO sample, $\mathrm{m}_{\mathrm{WCO}}$ is the mass of WCO weighted and used in the titration process analysis, 56.11 is the molar mass of $\mathrm{KOH}$, and 0.1 is the molar concentration of the $\mathrm{KOH}$ solution used.

Samples 1-4 of Table 7 were biodiesel products obtained after catalytic stability $(\# 1=$ product obtained after the first catalytic stability test), while \#5 sample was biodiesel produced using the homogeneous catalyst as a reference for comparison. Since the limit value of acidity index is $0.50-0.60 \mathrm{mg} \mathrm{KOH} / \mathrm{g}$ oil, it is possible to conclude that all the obtained samples were in accordance with the biodiesel quality EU standards (EN 14214). In order to compare the biodiesel obtained from the experimental method with the commercial diesel, a density measurement was performed with the help of a pycnometer. Measurements were made at $25^{\circ} \mathrm{C}$ and $40^{\circ} \mathrm{C}$ only, which are close to room temperature. The results are shown in Table 8.

Table 7. Acidity index (AI) values of biodiesel products obtained from catalytic stability tests.

\begin{tabular}{cccc}
\hline Biodiesel Samples & $\begin{array}{c}\text { Acidity Index (AI) } \\
\text { Control 1 }\end{array}$ & $\begin{array}{c}\text { Acidity Index (AI) } \\
\text { Control 2 }\end{array}$ & $\begin{array}{c}\text { Average Acidity Index } \\
\text { (AI) }\end{array}$ \\
\hline$\# 1$ & 0.57 & 0.56 & $0.57 \pm 1.3 \%$ \\
$\# 2$ & 0.55 & 0.53 & $0.54 \pm 2.6 \%$ \\
$\# 3$ & 0.42 & 0.44 & $0.43 \pm 1.6 \%$ \\
$\# 4$ & 0.56 & 0.55 & $0.56 \pm 1.3 \%$ \\
$\# 5$ & 0.55 & 0.56 & $0.56 \pm 1.3 \%$ \\
\hline
\end{tabular}


Table 8. Density of all samples (biodiesel, blended biodiesel-treated WCO, and blended biodieselhydrotreated kerosene $(\mathrm{HK}))$ at $25^{\circ} \mathrm{C}$ and $40^{\circ} \mathrm{C}$.

\begin{tabular}{|c|c|c|}
\hline Sample & \multicolumn{2}{|c|}{ Density $\left(\mathrm{kg} / \mathrm{m}^{3}\right)$} \\
\hline Biodiesel by homogeneous method & \multicolumn{2}{|c|}{$865.0\left(25^{\circ} \mathrm{C}\right)$} \\
\hline Biodiesel by heterogeneous method (first try of catalytic stability test) & $890.5\left(25^{\circ} \mathrm{C}\right)$ & $842.2\left(40^{\circ} \mathrm{C}\right)$ \\
\hline Biodiesel by heterogeneous method (second try of catalytic stability test) & $889.9\left(25^{\circ} \mathrm{C}\right)$ & $839.5\left(40^{\circ} \mathrm{C}\right)$ \\
\hline Biodiesel by heterogeneous method (third try of catalytic stability test) & $892.7\left(25^{\circ} \mathrm{C}\right)$ & $841.3\left(40^{\circ} \mathrm{C}\right)$ \\
\hline Biodiesel by heterogeneous method (four try of catalytic stability test) & $919.8\left(25^{\circ} \mathrm{C}\right)$ & $868.6\left(40^{\circ} \mathrm{C}\right)$ \\
\hline Biodiesel according to EN 14214 & \multicolumn{2}{|c|}{$860-900\left(15^{\circ} \mathrm{C}\right)$} \\
\hline Treated oil & $925.0\left(25^{\circ} \mathrm{C}\right)$ & $877.6\left(40^{\circ} \mathrm{C}\right)$ \\
\hline Jet-A1 & \multicolumn{2}{|c|}{$793.8\left(25^{\circ} \mathrm{C}\right)$} \\
\hline Blend of HK fuel (1\% biodiesel additive) & \multicolumn{2}{|c|}{$793.6\left(25^{\circ} \mathrm{C}\right)$} \\
\hline Blend of HK fuel ( $2 \%$ biodiesel additive) & \multicolumn{2}{|c|}{$794.8\left(25^{\circ} \mathrm{C}\right)$} \\
\hline Blend of HK fuel ( $3 \%$ biodiesel additive) & \multicolumn{2}{|c|}{$795.0\left(25^{\circ} \mathrm{C}\right)$} \\
\hline Blend of HK fuel (5\% biodiesel additive) & \multicolumn{2}{|c|}{$796.2\left(25^{\circ} \mathrm{C}\right)$} \\
\hline Blend of HK fuel ( $10 \%$ biodiesel additive) & \multicolumn{2}{|c|}{$801.9\left(25^{\circ} \mathrm{C}\right)$} \\
\hline Jet-A1 specifications & \multicolumn{2}{|c|}{$775.0-840.0\left(15^{\circ} \mathrm{C}\right)$} \\
\hline
\end{tabular}

The same procedure was applied for jet fuel (JET-A1) and blended biodiesel-JET-A1 samples. For this test, at first the pycnometer weight was measured when empty (M0), then the pycnometer was filled with distilled water (reference fluid) and heated in a bath set at $40{ }^{\circ} \mathrm{C}$ for $5 \mathrm{~min}$. After heating, the mass of water plus the pycnometer $\left(\mathrm{MH}_{2} \mathrm{O}\right)$ was measured and recorded again. The same procedure was then applied to biodiesel samples $\left(\mathrm{M}_{\text {mixture }}\right)$ obtained from the catalytic stability tests and also to the blended samples of $1 \%, 2 \%, 3 \%, 5 \%$, and $10 \%\left(\mathrm{~W}_{\text {biodiesel }} / \mathrm{W}_{\text {jet fuel A1 }}\right)$. Table 8 shows these results. The calculation of density $(\rho)$ values was made through Equation (3):

$$
\rho=\left(\frac{\mathrm{M}_{\text {mixture }}-\mathrm{M} 0}{\mathrm{MH}_{2} \mathrm{O}-\mathrm{M} 0}\right) \cdot \rho \mathrm{H}_{2} \mathrm{O}
$$

Measurements for biojet fuel blends were carried out at room temperature since the jet fuel has a flash point of $38^{\circ} \mathrm{C}$. Ambient temperature at operation was $25^{\circ} \mathrm{C}$. According to these results, all biodiesel samples from the catalytic stability tests were in accordance with the quality parameters defined for biodiesel under the European standard EN 14214, which defines density limits between $860-900 \mathrm{~kg} \cdot \mathrm{m}^{-3}$. Regarding JET-A1, quality standards for this jet fuel define a range of density between $775-840 \mathrm{~kg} \cdot \mathrm{m}^{-3}$, so to add biodiesel to JET-A1 fuel until achieving $10 \%(v / v)$, basically keeps the density of these mixtures within the same quality limits, which means that no relevant differences were observed. The water bath was also used to quantify kinematic viscosity at $40{ }^{\circ} \mathrm{C}$ and the capillary viscosimeter was fixed in the water bath. The spilled product from the large end of the viscosimeter was brought to the upper phase line level by means of a pump to cross to the other side. After the pump was removed, the timer was started. The timer was kept and time was recorded until the liquid level reached the lower phase line. For the same reason, measurements were made at $25^{\circ} \mathrm{C}$ for the biojet-fuel-blended samples. The values of kinematic viscosity at $25^{\circ} \mathrm{C}$ and $40{ }^{\circ} \mathrm{C}$ are highlighted in Table 9. The equation used for calculating kinematic viscosity values was Equation (4):

$$
\frac{\mu}{\mu \text { oil }}=\frac{\mathrm{t} \cdot \rho}{\text { toil } \cdot \rho \text { oil }} \text {. }
$$


Table 9. Kinematic viscosity of all samples (biodiesel and blend of biodiesel, treated oil, and HK).

\begin{tabular}{cc}
\hline Sample & Kinematic Viscosity $\left(\mathbf{m m}^{\mathbf{2}} \cdot \mathbf{s}^{\mathbf{- 1}}\right)$, \\
Biodiesel by homogeneous method & $\mathbf{4 0}{ }^{\circ} \mathbf{C}$ \\
\hline Biodiesel by heterogeneous method (first try out of catalytic stability test) & 3.50 \\
Biodiesel by heterogeneous method (second try out of catalytic stability test) & 3.72 \\
Biodiesel by heterogeneous method (third try out of catalytic stability test) & 3.52 \\
Biodiesel by heterogeneous method (four try out of catalytic stability test) & 3.60 \\
Biodiesel according to EN 14214 & 12.6 \\
Treated oil & $3.5-5.0$ \\
Jet-A1 & 32.9 \\
Blend of HK fuel (1\% biodiesel additive) & $1.00\left(^{*}\right)$ \\
Blend of HK fuel (2\% biodiesel additive) & $1.03\left(^{*}\right)$ \\
Blend of HK fuel (3\% biodiesel additive) & $1.04\left(^{*}\right)$ \\
Blend of HK fuel (5\% biodiesel additive) & $1.07\left(^{*}\right)$ \\
Blend of HK fuel (10\% biodiesel additive) & $1.10\left(^{*}\right)$ \\
\hline
\end{tabular}

$\left(^{*}\right)$-Measures performed at $25{ }^{\circ} \mathrm{C}$ and these specific values represent the ratio $\left(\mu / \mu_{\mathrm{jet}-\mathrm{A} 1}\right)$ at this temperature.

Biodiesel sample viscosity results showed that all analyzed samples from the catalytic stability tests, with the exception of the fourth sample, were in accordance with the quality limits defined by EN 14214, as kinematic viscosity of FAME biodiesel must be between 3.5 and $5.0 \mathrm{~mm}^{2} \cdot \mathrm{s}^{-1}$ or cSt. The fourth transesterification batch showed a higher value of viscosity, which was related to the low value of FAME content $(\approx 28 \%)$ achieved and far from the standard quality limits.

Lower FAME content meant less biodiesel and high oil content, because the viscosity of WCO was significantly higher than the biodiesel. On the other hand, for the blended biodiesel samples in the HK fuel, the ratio between the kinematic viscosity of a blended sample $(\mu)$ and the kinematic viscosity of pure $\mathrm{HK}\left(\mu_{\mathrm{jet}-\mathrm{A} 1}\right)$ at $25^{\circ} \mathrm{C}$ slightly increased with an increase in blended FAME content $(\%)$. This correlation was linear and it was calculated with the blended samples prepared, $1 \%, 2 \%, 3 \%$, $5 \%$, and $10 \%\left(\mathrm{~W}_{\text {biod. }} / \mathrm{W}_{\text {jet-A1 }}\right)$ of the heterogeneous biodiesel produced, and HK fuel supplied by the Portuguese refining oil company. This linear correlation is presented in Figure 11. A maximum increase of $10 \%$ in kinematic viscosity was observed for the blended biodiesel up to $5 \%$ (by weight) in the HK fossil fuel, which meant that significant changes in HK viscosity and lubricity were not observed. Beyond this point, the kinematic viscosity of $\mathrm{HK}$ fuel, at $25^{\circ} \mathrm{C}$, started to increase significantly, thus compromising its lubricity. Further studies at significant lower temperatures must be performed to understand blended biodiesel in the lubricity behavior of hydrotreated kerosene (HK).

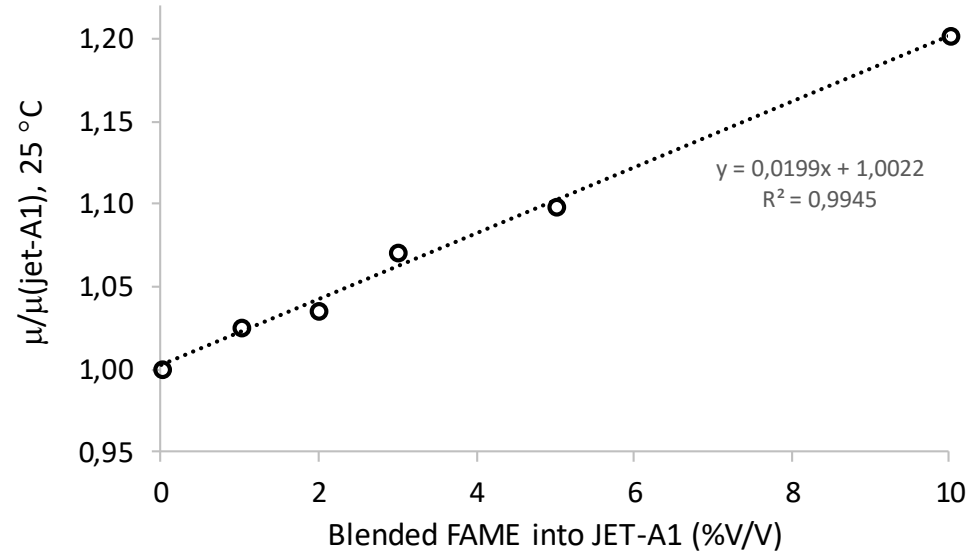

Figure 11. Linear correlation between $\mu / \mu_{(\text {jet-A1) }}$ at $25^{\circ} \mathrm{C}$ and blended biodiesel in JET-A1 (HK). 


\section{Conclusions}

At the end of this study, it is possible to conclude that waste cooking oils (WCO) can be used in order to valorize an important liquid waste, thus reducing GHG emissions, and also to use renewable primary energy sources (biomass) instead of non-renewable sources (diesel from crude oil). WCO used as raw materials have been improved and in this research work, this concept was achieved, since it was possible to produce FAME biodiesel from treated WCO and Ca-rich seafood wastes as alkaline heterogeneous catalysts. The catalytic activity and stability tests prove that these materials are suitable to be used as solid catalysts in biodiesel production, avoiding the current disadvantages of the catalytic homogeneous processes. Nevertheless, the acidity index of the WCO must be lower, otherwise, soap formation (from undesirable saponification reactions) will decrease biodiesel mass yield, since the separation process of these soaps will drag along a significant quantity of biodiesel. For that reason, WCO was pre-treated previously, with drying and neutralization processes. If not, this will affect the whole process, slow down the catalyst activity, and also decrease biodiesel purity, thereby reducing FAME yield and it will present difficulties in the separation and purification processes. It may even cause gelification of the liquid product, making it impossible to reach the desirable purity due to the undesirable production of calcium diglyceroxide, as reported before. Furthermore, by using a natural and calcium-rich heterogeneous catalyst, the biodiesel operating costs can be considerably reduced and the biodiesel can even be considered as a good alternative, since these catalyst components are easy to find and use. During the transesterification reaction, the best operating conditions achieved were $5 \%\left(\mathrm{~W}_{\text {cat. }} / \mathrm{W}_{\mathrm{oil}}\right), 12: 1$ methanol/WCO molar ratio, $60{ }^{\circ} \mathrm{C}$, and $2 \mathrm{~h}$ of reaction time, thus producing a remarkable FAME conversion result higher than $99.5 \%$, similar to current catalytic alkaline homogeneous processes with $\mathrm{NaOH}, \mathrm{KOH}$, or $\mathrm{NaOMe}$. The repeatability and catalytic stability tests showed that the activity and stability of these Ca-rich waste materials made them very good catalysts in the production of FAME biodiesel by heterogeneous catalysis processes. To ensure the quality of synthesized heterogeneous biodiesel samples, some quality parameters were quantified, according to the European standard for biodiesel (EN 14214), like density, kinematic viscosity, acidity index, and FAME content. These parameters were applied for the four samples of the catalytic stability tests and with the exception of the fourth sample, the other samples showed that all values were in accordance with the standard limits, including the FAME content, which was found to be higher than $99.5 \%$ (the established standard minimum is $96.5 \%$ ). The preparation of current HK fuel and FAME biodiesel blends was an important task to quantify the viscosity of these mixtures. $1 \%, 2 \%, 3 \%, 5 \%$, and 10\% synthesized heterogeneous FAME biodiesel samples were added to HK fuel and compared with pure JET-A1 viscosity. The data obtained from the compatibility tests were found to be the same for almost all the times recorded. Only for the blend of $10 \%$ (biodiesel), the difference was $11 \mathrm{~s}$ more. So, it is possible to conclude that, with the exception of the $10 \%$ blend, the added biodiesel between $1 \%$ and $5 \%$ had no significant effect on the fluidity of the $\mathrm{HK}$ fuel, at $25{ }^{\circ} \mathrm{C}$. According to the obtained results, the increment of kinematic viscosity at $25^{\circ} \mathrm{C}$ in the blended biojet fuel was only approximately 0.02 for each $1 \%(v / v)$ FAME biodiesel added to the HK fuel, which was a very low increase. In further studies, there is a need to perform more significant compatibility studies of blended FAME biodiesel into JET-A1 fuel, at other temperatures, especially, with very cold temperatures $\left(-20{ }^{\circ} \mathrm{C}\right.$ until $\left.-50{ }^{\circ} \mathrm{C}\right)$.

Author Contributions: Conceptualization, J.F.G. and J.F.P.; execution and discussion of the results, S.O. and T.C.; writing-review and editing, J.F.G., J.F.P., M.T.S. and J.V.P.

Funding: This research was funded by FCT (Fundação para a Ciência e Tecnologia), grant number PTDC/EMS-ENE/4865/2014.

Acknowledgments: The authors thank Maria Celeste Serra from CEEQ/ISEL for equipment availability; Beatriz Alexandre and Catarina Chaves from CLC for supplying HK fossil fuel liquid sample from the Portuguese refining crude oil company, GALP Energia. The authors also thank Isabel Nogueira from MicroLab at IST-UL for collecting SEM images and EDS data, and Ana Ribeiro from CQE/IST-UL for XRD diffractograms and for the use of the $\mathrm{N}_{2}$ adsorption equipment. The authors are also thankful to PHARMALAB lab at ISEL and João Costa for acquiring the DLC lines. 
Conflicts of Interest: The authors declare no conflicts of interest.

\section{References}

1. Wang, W.; Tao, L.; Markham, J.; Zhang, Y.; Tan, E.; Batan, L.; Warner, E.; Biddy, M. Review of Biojet Fuel Conversion Technologies; National Renewable Energy Laboratory: Golden, CO, USA, 2016.

2. Deane, P.; Shea, R.; Gallachoir, B.; Buchholz, D. Biofuels for Aviation; Rapid Response Energy Brief; Insight-E: Brussels, Belgium, 2015.

3. Korres, D.M.; Karonis, D.; Lois, E.; Linck, M.B.; Gupta, A.K. Aviation fuel JP-5 and biodiesel on a diesel engine. Fuel 2008, 87, 70-78. [CrossRef]

4. Hari, T.K.; Yaakob, Z.; Binitha, N.N. Aviation biofuel from renewable resources: Routes, opportunities and challenges. Renew. Sustain. Energy Rev. 2015, 42, 1234-1244. [CrossRef]

5. Tunca, I. Biyodizel hakkında herşey. Biyodizel Derg. 2013, 8, 41-49. (In Turkish)

6. Bartan, A. Biyodizel Üretiminde Heterojen Katalizör Geliştirilmesi. Master's Thesis, Gazi Üniversitesi, Ankara, Turkey, 2009. (In Turkish)

7. Puna, J.; Gomes, J.; Correia, M.J.N.; Dias, A.S.; Bordado, J.; Puna, J.; Correia, M.J.N.; Dias, A.P.S. Advances on the development of novel heterogeneous catalysts for transesterification of triglycerides in biodiesel. Fuel 2010, 89, 3602-3606. [CrossRef]

8. Puna, J.F.; Correia, M.J.N.; Dias, A.P.S.; Gomes, J.; Bordado, J. Biodiesel production from waste frying oils over lime catalysts. React. Kinet. Mech. Catal. 2013, 109, 405-415. [CrossRef]

9. Marchetti, J.M.; Miguel, V.; Errazu, A. Possible methods for biodiesel production. Renew. Sustain. Energy Rev. 2007, 11, 1300-1311. [CrossRef]

10. Demirbaş, A. Progress and recent trends in biodiesel fuels. Energy Convers. Manag. 2009, 50, 14-34. [CrossRef]

11. Boro, J.; Deka, D.; Thakur, A.J. A review on solid oxide derived from waste shells as catalyst for biodiesel production. Renew. Sustain. Energy Rev. 2012, 16, 904-910. [CrossRef]

12. BP Statistical Review of World Energy December 2018. Available online: https://www.bp.com/content/dam/ bp/business-sites/en/global/corporate/pdfs/energy-economics/statistical-review/bp-stats-review-2019-fullreport.pdf (accessed on 25 October 2019).

13. Ozcimen, D.; Yucel, S. Novel methods in biodiesel production. Proc. Biofuel Eng. Process Technol. 2011, 8 , 353-384.

14. Shan, R.; Zhao, C.; Lv, P.; Yuan, H.; Yao, J. Catalytic applications of calcium rich waste materials for biodiesel: Current state and perspectives. Energy Convers. Manag. 2016, 127, 273-283. [CrossRef]

15. Puna, J.F.; Gomes, J.F.; Bordado, J.C.; Correia, M.J.N.; Dias, A.P.S. Biodiesel production over lithium modified lime catalysts: Activity and deactivation. Appl. Catal. A Gen. 2014, 470, 451-457. [CrossRef]

16. Gomes, J.F.; Puna, J.F.; Gonçalves, L.M.; Bordado, J.C. Study on the use of MgAl hydrotalcites as solid heterogeneous catalysts for biodiesel production. Energy 2011, 36, 6770-6778. [CrossRef]

17. Granados, M.L.; Poves, M.Z.; Alonso, D.M.; Mariscal, R.; Galisteo, F.C.; Moreno-Tost, R.; Santamaria, J.; Fierro, J. Biodiesel from sunflower oil by using activated calcium oxide. Appl. Catal. B Environ. 2007, 73, 317-326. [CrossRef]

18. Dias, A.P.S.; Puna, J.; Gomes, J.; Correia, M.J.N.; Bordado, J. Biodiesel production over lime. Catalytic contributions of bulk phases and surface Ca species formed during reaction. Renew. Energy 2016, 99, 622-630. [CrossRef]

19. Catarino, M.; Ramos, M.; Dias, A.P.S.; Santos, M.T.; Puna, J.F.; Gomes, J.F. Calcium Rich Food Wastes Based Catalysts for Biodiesel Production. Waste Biomass Valorization 2017, 8, 1699-1707. [CrossRef]

20. Semwal, S.; Arora, A.; Badoni, P.; Tuli, D. Biodiesel production using heterogeneous catalysts. Bioresour. Technol. 2011, 102, 2151-2161. [CrossRef] [PubMed]

21. Marwaha, A.; Rosha, P.; Mohapatra, S.K.; Mahla, S.K.; Dhir, A. Waste materials as potential catalysts for biodiesel production: Current state and future scope. Fuel Process. Technol. 2018, 181, 175-186. [CrossRef]

22. Lee, S.L.; Wong, Y.C.; Tan, Y.P.; Yew, S.Y. Transesterification of palm oil to biodiesel by using waste obtuse horn shell-derived CaO catalyst. Energy Convers. Manag. 2015, 93, 282-288. [CrossRef]

23. Nakatani, N.; Takamori, H.; Takeda, K.; Sakugawa, H. Transesterification of soybean oil using combusted oyster shell waste as a catalyst. Bioresour. Technol. 2009, 100, 1510-1513. [CrossRef] [PubMed] 
24. Boey, P.L.; Maniam, G.P.; Hamid, S.A. Biodiesel production via transesterification of palm oil using waste mud crab (Scylla serrata) shell as a heterogeneous catalyst. Bioresour. Technol. 2009, 100, 6362-6368. [CrossRef] [PubMed]

25. Viriya-Empikul, N.; Krasae, P.; Nualpaeng, W.; Yoosuk, B.; Faungnawakij, K. Biodiesel production over Ca-based solid catalysts derived from industrial wastes. Fuel 2012, 92, 239-244. [CrossRef]

26. Viriya-Empikul, N.; Krasae, P.; Puttasawat, B.; Yoosuk, B.; Chollacoop, N.; Faungnawakij, K. Waste shells of mollusk and egg as biodiesel production catalysts. Bioresour. Technol. 2010, 101, 3765-3767. [CrossRef] [PubMed]

27. Piker, A.; Tabah, B.; Perkas, N.; Gedanken, A. A green and low-cost room temperature biodiesel production method from waste oil using eggshells as catalyst. Fuel 2016, 182, 34-41. [CrossRef]

28. Kaewdaeng, S.; Sintuya, P.; Nirunsin, J. Biodiesel production using CaO from river snail shell ash as catalyst. Energy Procedia 2017, 138, 937-942. [CrossRef]

29. Birla, A.; Singh, B.; Upadhyay, S.; Sharma, Y. Kinetics studies of synthesis of biodiesel from waste frying oil using a heterogeneous catalyst derived from snail shell. Bioresour. Technol. 2012, 106, 95-100. [CrossRef] [PubMed]

30. Li, M.; Zheng, Y.; Chen, Y.; Zhu, X. Biodiesel production from waste cooking oil using a heterogeneous catalyst from pyrolyzed rice husk. Bioresour. Technol. 2014, 154, 345-348. [CrossRef] [PubMed]

31. Abdullah, S.H.Y.S.; Hanapi, N.H.M.; Azid, A.; Umar, R.; Juahir, H.; Khatoon, H.; Endut, A. A review of biomass-derived heterogeneous catalyst for a sustainable biodiesel production. Renew. Sustain. Energy Rev. 2017, 70, 1040-1051. [CrossRef]

32. Kulkarni, M.G.; Dalai, A.K. Waste Cooking OilAn Economical Source for Biodiesel: A Review. Ind. Eng. Chem. Res. 2006, 45, 2901-2913. [CrossRef]

33. Melero, J.A.; Iglesias, J.; Morales, G. Heterogeneous acid catalysts for biodiesel production: Current status and future challenges. Green Chem. 2009, 11, 1285-1308. [CrossRef]

34. Shan, R.; Lu, L.; Shi, Y.; Yuan, H.; Shi, J. Catalyst from renewable sources for biodiesel production. Energy Convers. Manag. 2018, 178, 277-289. [CrossRef]

35. Dias, A.P.S.; Puna, J.; Correia, M.J.N.; Nogueira, I.; Gomes, J.; Bordado, J. Effect of the oil acidity on the methanolysis performances of lime catalyst biodiesel from waste frying oils (WFO). Fuel Process. Technol. 2013, 116, 94-100. [CrossRef]

36. Lam, M.K.; Lee, K.T.; Mohamed, A.R. Homogeneous, heterogeneous and enzymatic catalysis for transesterification of high free fatty acid oil (waste cooking oil) to biodiesel: A review. Biotechnol. Adv. 2010, 28, 500-518. [CrossRef] [PubMed]

37. Kouzu, M.; Kasuno, T.; Tajika, M.; Sugimoto, Y.; Yamanaka, S.; Hidaka, J. Calcium oxide as a solid base catalyst for transesterification of soybean oil and its application to biodiesel production. Fuel 2008, 87, 2798-2806. [CrossRef]

38. Vujicic, D.; Comic, D.; Zarubica, A.; Micic, R.; Bošković, G. Kinetics of biodiesel synthesis from sunflower oil over $\mathrm{CaO}$ heterogeneous catalyst. Fuel 2010, 89, 2054-2061. [CrossRef]

39. Khemthong, P.; Luadthong, C.; Nualpaeng, W.; Changsuwan, P.; Tongprem, P.; Viriya-Empikul, N.; Faungnawakij, K. Industrial eggshell wastes as the heterogeneous catalysts for microwave-assisted biodiesel production. Catal. Today 2012, 190, 112-116. [CrossRef]

40. Miladinović, M.R.; Krstić, J.B.; Tasić, M.B.; Stamenković, O.S.; Veljković, V.B. A kinetic study of quicklime-catalyzed sunflower oil methanolysis. Chem. Eng. Res. Des. 2014, 92, 1740-1752. [CrossRef]

41. Chouhan, A.S.; Sarma, A. Modern heterogeneous catalysts for biodiesel production: A comprehensive review. Renew. Sustain. Energy Rev. 2011, 15, 4378-4399. [CrossRef]

(C) 2019 by the authors. Licensee MDPI, Basel, Switzerland. This article is an open access article distributed under the terms and conditions of the Creative Commons Attribution (CC BY) license (http://creativecommons.org/licenses/by/4.0/). 